\title{
Gigi Tiruan Overlay Thermoplastic Resin Pada Pasien Celah Bibir Dan Palatum
}

\author{
Elka Ayu Amalia, Heriyanti Amalia Kusuma, dan Endang Wahyuningtyas
}

Bagian Prostodonsia Fakultas Kedokteran Gigi UGM

JI Denta No 1 Sekip Utara Yogyakarta; e-mail: drg.elka@gmail.com

\begin{abstract}
ABSTRAK
Kasus celah bibir dan palatum, adalah kasus yang memiliki tingkat kesulitan lebih tinggi dalam hal perbaikan bila dibandingkan dengan kasus kecacatan lain yang disebabkan oleh cacat bawaan maupun dapatan lain. Karena kasus celah bibir dan palatum meminta perhatian khusus pada tahap-tahap perbaikannya, serta memerlukan kolaborasi antar disiplin ilmu kedokteran untuk mendapatkan hasil yang optimal. Prostodonsi adalah salah satu bidang kedokteran gigi yang memegang peranan menentukan hasil akhir dari rangkaian perawatan yang telah dilakukan. Gigi tiruan overlay adalah gigi tiruan lepasan yang digunakan untuk mengurangi penyempitan rahang atas dan perbedaan dalam dimensi vertikal. Tujuan dari artikel ini adalah membahas perawatan yang lebih nyaman dengan gigi tiruan overlay thermoplastic resin untuk kasus celah bibir dan palatum. Seorang pasien perempuan, 25 tahun, datang dengan keluhan ingin perbaikan estetik pada regio anterior rahang atas, untuk menutupi defek sisa hasil operasi penyatuan celah palatum yang telah dilakukan ketika balita. Tatalaksana kasus: 1) Anamnesa, 2) Pemeriksaan klinis dan radiografis, 3) Pencetakan model studi, 4) Pencetakan model kerja, 5) Pemasangan pada artikulator, 6) Penyusunan gigi, 7) Pasang coba model malam, 8) Processing laboratorium, 9) Insersi, 10) Kontrol. Kesimpulan: Perawatan pasien celah palatum dengan gigi tiruan overlay thermoplastic resin memberikan kenyamanan, perbaikan estetis sehingga menimbulkan dampak psikologis yang baik pada pasien .
\end{abstract}

Maj Ked Gi. Juni 2014; 21(2):171-177

Kata kunci : Gigi tiruan overlay, kenyamanan, perbaikan estetis.

ABSTRACT: Thermoplastic Resin Overlay Denture On Cleft Lip And Palate Patient (A Case Report). Background: Cleft lip and palate has a degree of difficulities in habilitativeness among other congenital or acquired handicaps. Because this case requires a special attention on the habilitation stage, also requires an interdiciplinary collaboration in medical professions in order to achieve optimal results. Prosthodontics is a part in dentistry that has a role in determining the final results of a series of treatments that have been performed. Overlay denture is a removable prosthesis which are used to alleviate maxillary constriction and discrepancies in vertical dimension. Purpose: To give more comfortable treatment with overlay denture on cleft lip and palate case. Case: A 25 years old female patient, with the chief complaint of the aesthetic on her maxillary anterior region. Requires a treatment to covered her defect, post cleft lip and palate operations that have been performed when she was a child. Case management: 1) Anamnesis, 2) Clinical and radiographic examination, 3) Study model impressions, 4) Working model impressions, 5) Articulator mounting, 6) Artificial teeth arrangement, 7) Wax model try-in, 8) Laboratorium processing, 9) Insertion, 10) Control. Conclusion: Treatment of a cleft lip and palate case with a thermoplastic resin overlay denture can delivered comfort, and aesthetic improvement which can gives the patient a positive physiological impact.

Maj Ked Gi. Juni 2014; 21(2):171-177

Key words: Overlay denture, comfort, aesthetic improvement

\section{PENDAHULUAN}

Pembuatan gigi tiruan lepasan pada kasus celah bibir dan palatum merupakan kasus yang memiliki tingkat kesulitan tinggi dalam hal perbaikan bila dibandingkan dengan kasus kecacatan lain yang disebabkan oleh cacat bawaan maupun dapatan. Perawatan untuk celah bibir dan palatum merupakan kasus yang unik karena memerlukan kolaborasi antar disiplin ilmu kedokteran. ${ }^{1}$ Kerjasama antara dokter spesialis bedah plastik, dokter gigi spesialis ortodonsia dan dokter gigi spesialis prostodonsia diperlukan pada saat pasien baru lahir dan berlanjut ketika pasien beranjak dewasa agar mendapatkan hasil yang optimal.

Rehabilitasi pada pasien celah bibir dan palatum merupakan perawatan yang bersifat individual, berbeda kebutuhan sesuai dengan kasus yang terjadi pada masing-masing pasien. ${ }^{2}$ Perbaikan bergantung pada tingkat keparahan malformasi serta usia pasien saat mulai dilakukan perawatan. 
Perawatan yang ideal yaitu penutupan defek dengan bone graft maupun perawatan ortodonsi, namun pada kenyataannya, banyak kasus yang diselesaikan dengan perawatan prostodonsi. Perawatan prostodonsia masih menjadi pilihan utama karena pertimbangan besarnya biaya yang harus dikeluarkan pasien pada saat memulai perbaikan celah bibir dan palatum hingga mendapatkan hasil yang memuaskan. ${ }^{3}$

Pada kasus celah bibir dan palatum, letak defek pada wajah yang merupakan pusat perhatian, menjadikan gigi tiruan selain harus dapat memperbaiki fungsi kunyah serta bicara, juga harus dapat mengembalikan rasa percaya diri pasien di kehidupan sosialnya. Pentingnya penampilan wajah merubah prioritas prinsip pembuatan gigi tiruan, sehingga menjadikan estetis sebagai hal utama. ${ }^{1}$ Perbaikan estetis serta pengembalian fungsi normal gigi menjadi suatu tantangan untuk perawatan prostodonsia karena adanya frenula pada bibir, defisiensi jaringan tulang dan keratinisasi mukosa rongga mulut. ${ }^{3}$

Celah bibir dan palatum dikategorikan menjadi dua bagian : a. Two cleft segments (unilateral cleft), memiliki dua bagian yang disebut long/ non cleft/ attached segment (1), short/ cleft segment (2). (Gambar 1a).b. Three cleft segments (bilateral cleft), memiliki tiga bagian yang disebut lateral segment (1) \& (3), premaxillary segment/ premaxilla (2). (Gambar 1b) ${ }^{1}$
Operasi penyatuan celah bibir dan palatum memiliki beberapa "efek samping" yang perlu diperhatikan sebelum pembuatan gigi tiruan, yaitu adanya perubahan pada:

a).Maksila; terjadi konstriksi yang dapat menghambat pertumbuhan maksila ke arah lateral dan anterior, b).Dimensi vertikal; yang dapat menghambat pertumbuhan maksila ke arah bawah dan depan, c).Gigi; terjadinya hypoplastic, supernumerary dan hilangnya gigi, d).Proses bicara; terganggunya kualitas suara dan artikulasi, e).Lengkung rahang, terjadinya interarch discrepancy atau jarak antar lengkung rahang, maupun maxillomandibular discrepancy atau jarak antar rahang, yang disebabkan perbedaan bentuk rahang atas dan bawah. ${ }^{1,3}$

Penatalaksanaan perbaikan celah pada pasien dewasa secara umum dapat dibagi menjadi dua bagian, yaitu pertama :

pasien tanpa defek palatal, dan kedua, pasien dengan defek palatal (baik defek yang tidak diperbaiki maupun defek sisa setelah operasi perbaikan). ${ }^{4}$

Perawatan prostodonsi yang dapat dilakukan pada pasien dengan celah bibir dan palatum yaitu: implan, gigi tiruan tetap, overdenture, overlay, gigi tiruan sebagian lepasan dengan obturator, gigi tiruan lengkap dengan obturator, gigi tiruan sebagian lepasan. . $3,3,4,5^{-6}$

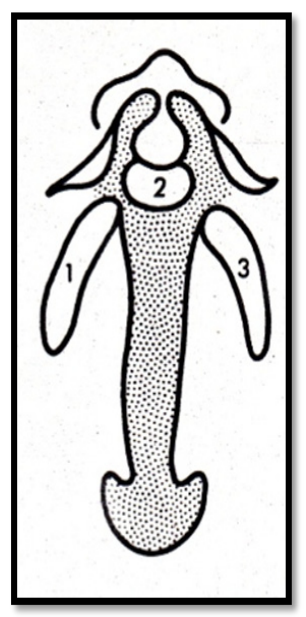

Gambar 1b. Bilateral cleft 


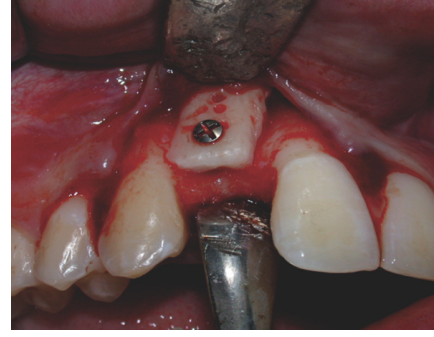

Gambar 2a. Penambahan bone graft pada defek palatum. ${ }^{3}$

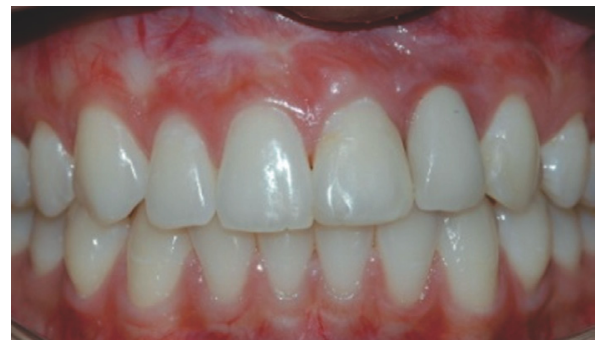

Gambar 2b. Implan pada gigi insisiv lateral kiri. ${ }^{3}$

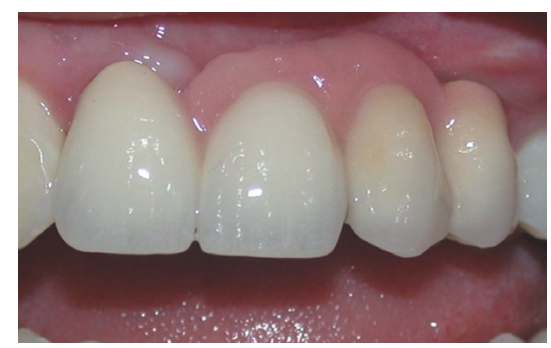

Gambar 3. Gigi tiruan tetap pada kedua gigi insisiv sentral, insisiv lateral kiri dan kaninus kiri. ${ }^{3}$

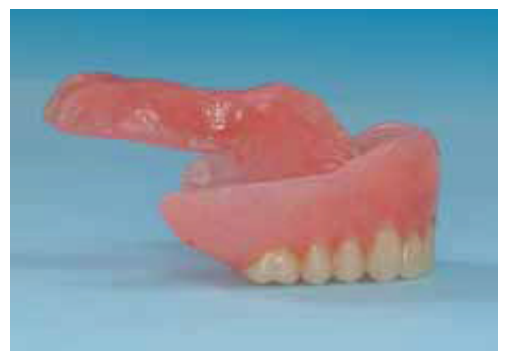

Gambar 4. Gigi tiruan sebagian lepasan dengan obturator. ${ }^{4}$

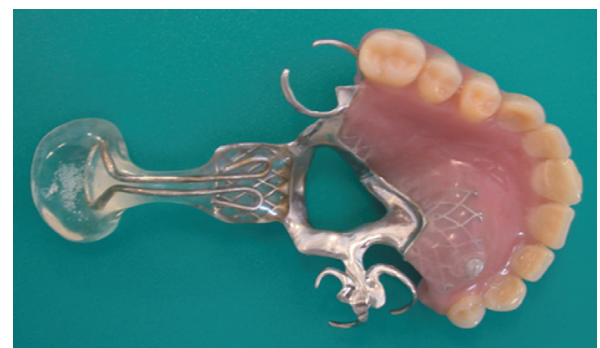

Gambar 5. Gigi tiruan lengkap dengan obturator. ${ }^{3}$

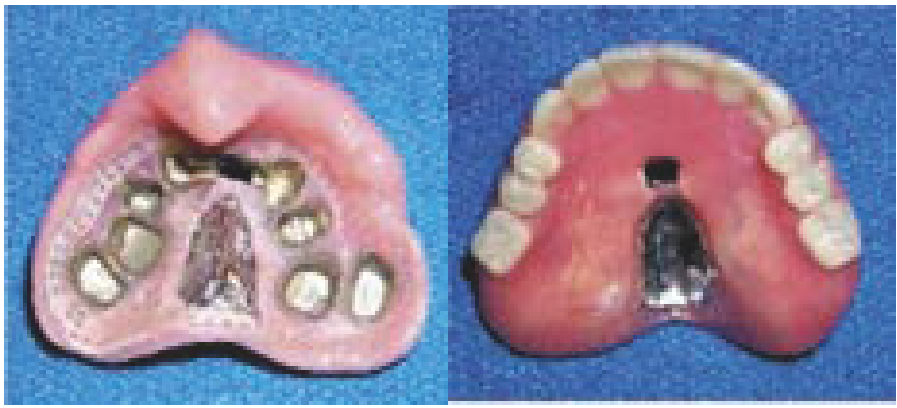

Gambar 6. Overdenture dengan kaitan teleskopik. ${ }^{5}$

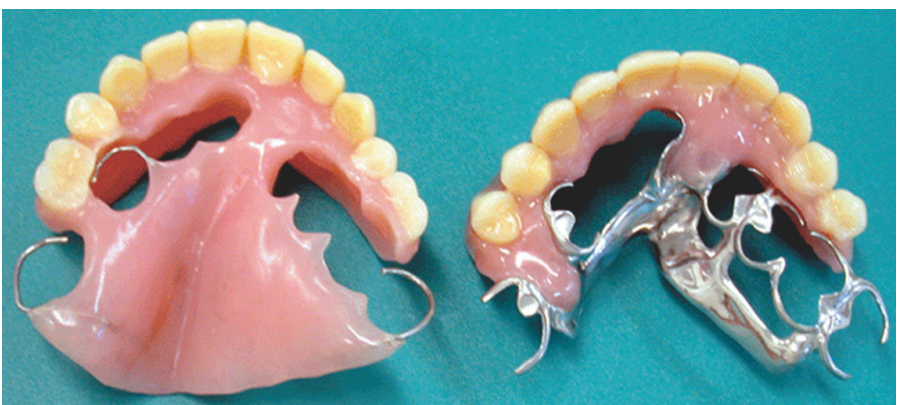

Gambar 7. Overlay denture akrilik dengan kawat dan dengan frame. ${ }^{3}$ 


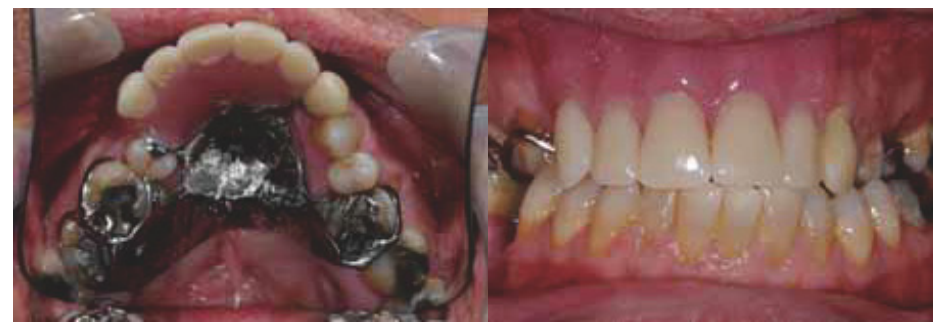

Gambar 8. Gigi tiruan sebagian lepasan. ${ }^{4}$

Gigi tiruan overlay adalah gigi tiruan lepasan yang digunakan untuk mengurangi penyempitan rahang atas, perbedaan dalam dimensi vertikal, menutupi maxilla yang terkonstriksi arah horizontal dengan sayap labial dan bukal di atas gigi dan ridge. Gigi tiruan overlay dapat berupa gigi tiruan lengkap maupun sebagian lepasan yang dibuat menutupi gigi atau akar gigi yang tidak diselubungi dengan koping di bawah permukaan plat gigi tiruan. ${ }^{7}$

Indikasi gigi tiruan overlay termasuk cacat bawaan (celah bibir dan palatum), oligodontia, ectodermal dysplasia, dan cleidocranial dysplasia. Pembuatan gigi tiruan overlay juga merupakan pilihan perawatan untuk kecacatan lain yang berhubungan dengan malformasi ataupun kehilangan gigi dan untuk pasien yang memiliki gigi dengan erosi maupun abrasi yang parah. ${ }^{8}$

Gigi tiruan overlay untuk kasus celah bibir dan palatum memiliki dua tipe yaitu: (Gambar 2)

a. Complete overlay, yaitu gigi tiruan overlay yang memiliki sayap labial serta anasir gigi yang menutupi seluruh lengkung anterior, dari molar pertama di satu sisi meluas ke molar pertama di sisi lain. Diindikasikan untuk kasus celah bibir dan palatum bilateral. b. Partial overlay, yaitu gigi tiruan overlay yang memiliki sayap labial serta anasir gigi yang menutupi hanya pada bagian defek/ celah saja. ${ }^{7}$

\section{KASUS}

Pasien perempuan usia 25 tahun datang ke klinik Prostodonsia RSGM Prof Soedomo FKG UGM ingin dibuatkan gigi tiruan baru. Pasien telah menggunakan gigi tiruan sebagian lepasan akrilik di rahang atas, namun tidak puas dengan estetisnya (Gambar 11). Pasien masih memiliki defek sisa pada palatum pasca operasi penyatuan celah palatum, namun defek pada bibir telah ditutup melalui prosedur operasi yang sama.

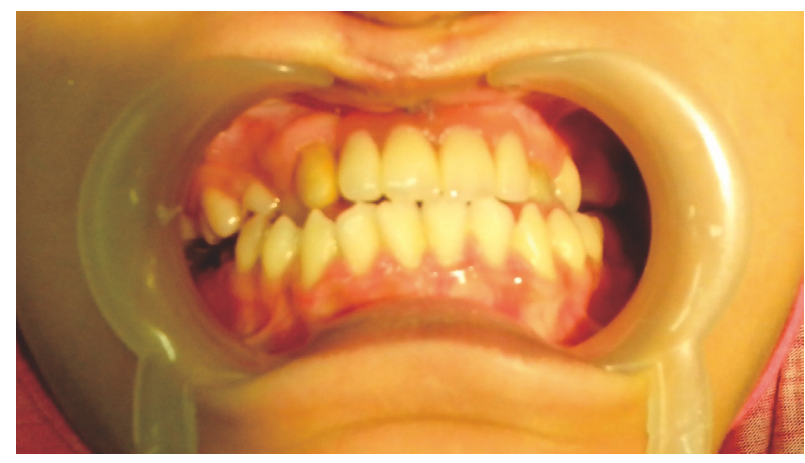

Gambar 11. Pasien dengan gigi tiruan sebagian lepasan akrilik

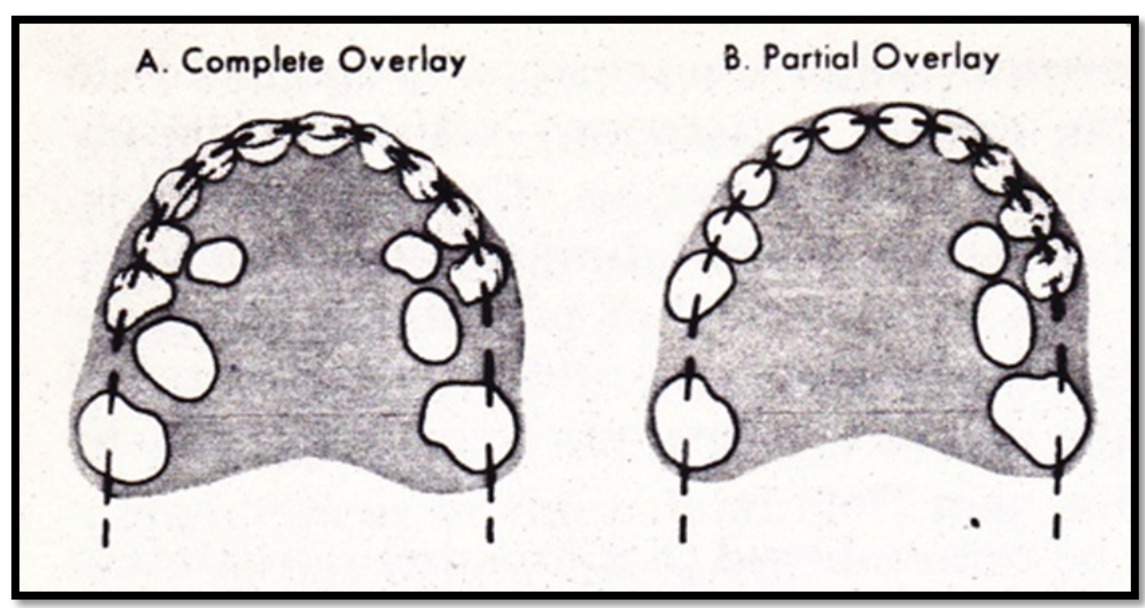

Gambar 10. Tipe overlay denture : complete overlay dan partial overlay 
Pada pemeriksaan klinis diketahui bahwa pasien tidak memiliki riwayat penyakit sistemik dan alergi. Pasien kehilangan gigi 11, 12, 21, 22 dan 24 pada rahang atas yang merupakan klasifikasi ApplegateKennedy Klas IV. Terdapat gigi 53 dalam kondisi baik. Gigi 13, 14, 15, 23, dan 25 terletakdi palatum, tidak sesuai seperti lengkung normal (Gambar 12a dan 12b). Kebersihan rongga mulut baik, tidak ditemukan adanya kalkulus. Rencana perawatan prostodonsi yang akan dilakukan yaitu gigi tiruan complete overlay thermoplastic resin.

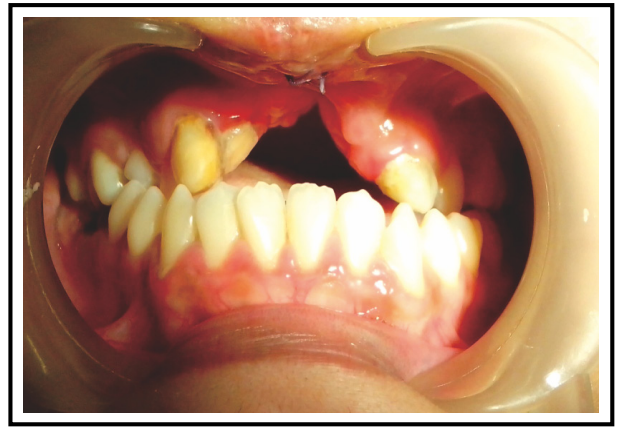

Gambar 12a. Defek tampak anterior

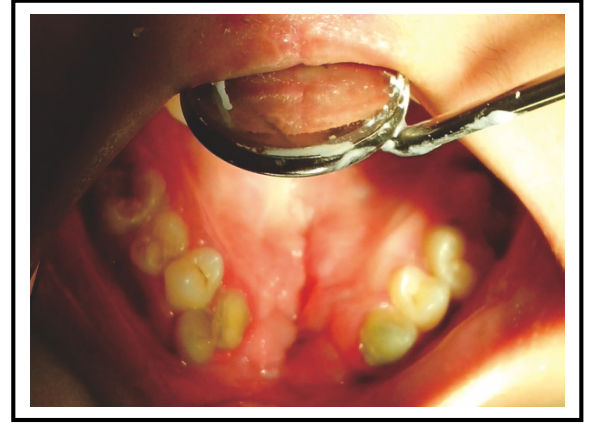

Gambar 12b. Defek tampak oklusal/ palatal

\section{METODE}

Tahap pembuatan gigi tiruan sebagian lepasan overlay thermoplastic resin :

Persiapan , yaitu antara lain dilakukan anamnesa, dilanjutkan dengan pemeriksaan klinis, baik ekstraoral maupun intraoral, pembuatan foto radiografik serta foto klinis, pencetakan model diagnostik dengan bahan cetak alginat dan terakhir dilakukan pencocokan warna gigi dengan shade guide ( VITAPAN).

Setelah tahap persiapan lalu dimulai dengan tahap pembuatan, yaitu:

pertama dilakukan pencetakan model kerja dengan bahan cetak alginat, kedua pembuatan desain gigi tiruan overlay, lalu dibuat gambar pola lengkung normal rahang bawah ,dan membuat gambar pola lengkung rahang atas dan pola lengkung normal rahang bawah, lalu dilakukan penyesuaian pola lengkung rahang atas dan bawah (Gambar 13).

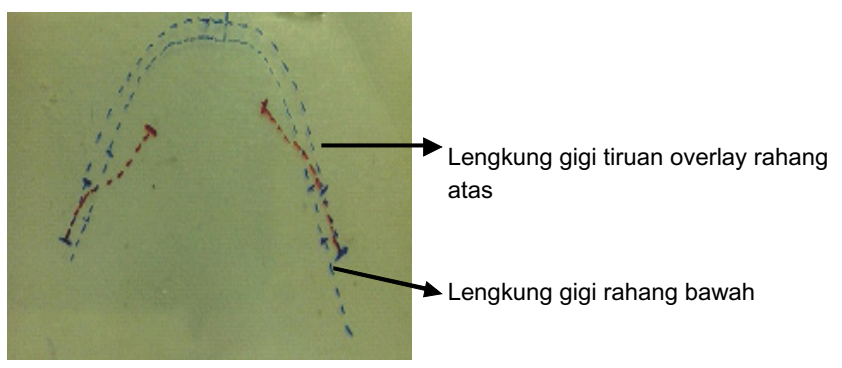

Gambar 13. Penyesuaian pola lengkung rahang atas-bawah. Garis merah = lengkung gigi rahang atas pasien; garis biru = lengkung gigi tiruan overlay yang disesuaikan dengan lengkung rahang bawah

Ketiga dibuat bite rim dengan menggunakan pola lengkung gigi tiruan overlay rahang atas yang sudah disesuaikan dengan pola lengkung normal, langkah keempat pembuatan catatan gigitan pada pasien dengan malam merah, dilanjutkan dengan penanaman model kerja di artikulator. Langkah kelima, dilakukan penyusunan anasir gigi, lalu dilakukan pasang coba model malam pada pasien (Gambar 14a dan 14b).

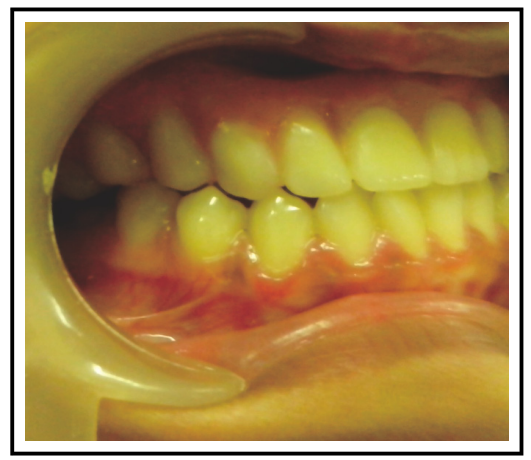

Gambar 14a. Tampak depan-samping

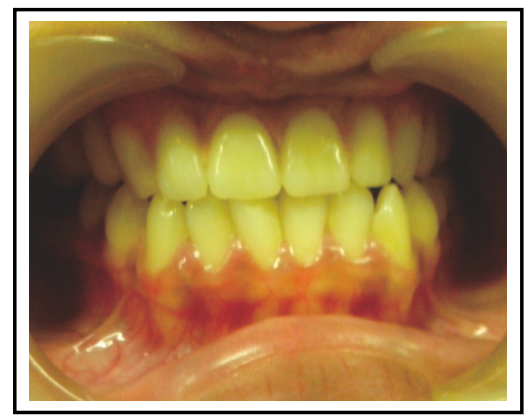

Gambar 14b. Tampak depan 
Setelah pasang coba, langkah keenam gigi tiruan diprocessing di laboratorium, setelah jadi, gigi tiruan diinsersikan ke pasien.

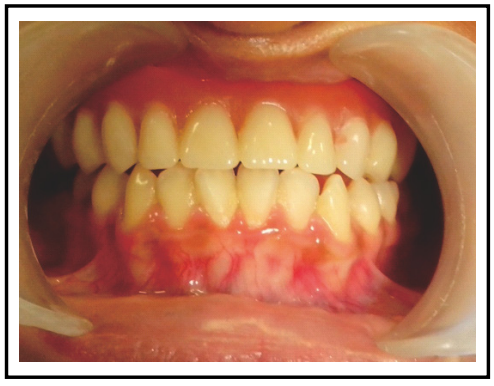

Gambar 15a. Tampak anterior watan prostodonsi yang sesuai dengan kondisi pasien saat ini yaitu gigi tiruan complete overlay thermoplastic resin yang sayap labial serta anasir giginya

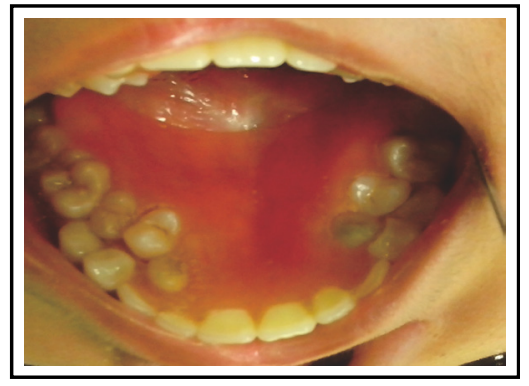

Gambar 15b. Tampak oklusal

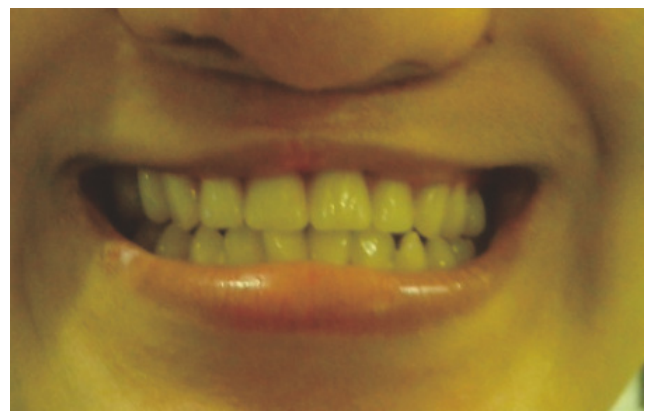

Gambar 16. Pasien dengan gigi tiruan overlay thermoplastic resin.

\section{PEMBAHASAN}

Pembuatan gigi tiruan overlay ditentukan oleh letak gigi caninus dan daerah anterior dari masingmasing segmen lateral. Gigi tiruan lepasan overlay dapat dibuat bila gigi caninus terletak sangat lingual dan tidak memiliki oklusi normal atau tidak mempunyai dukungan yang cukup pada sudut mulut.

Pada kasus ini, pasien pernah menggunakan gigi tiruan lepasan akrilik, namun desainnya hanya mengganti gigi yang hilang dengan posisi oklusi gigi anterior cross bite, sehingga profil pasien tampak cekung. Pasien mengalami konstriksi maksila ke arah anterior dan lateral. Pada pemeriksaan intraoral tidak tampak adanya gigi incisivus pada maksila, masih terdapat gigi 53 , dan gigi $13,14,15$, 23, dan 25 terletak lebih ke palatal. Rencana pera- menutupi seluruh lengkung anterior dari regio molar satu kanan atas sampai dengan regio molar satu kiri atas. Pembuatan pola gigi tiruan overlay dimulai dengan membuat pola lengkung rahang atas dan serta pola yang disesuaikan dengan pola lengkung rahang bawah yang normal, pembuatan pola bertujuan untuk mengkoreksi adanya perbedaan bentuk lengkung rahang atas dan bawah. Gigi tiruan overlay dibuat pada gigi $15,14,13,12,11$, $21,22,23,24$ dan 25 , dengan pelebaran sayap bukal ke gigi 16 dan 26 (wrap around) yang berfungsi sebagai retensi. Pelebaran plat dibuat untuk menutup defek di palatal serta untuk retensi.

Pembuatan gigi tiruan overlay dengan menyesuaikan lengkung gigi rahang bawah yang normal diharapkan dapat memperbaiki profil pasien. (Gambar 17) 


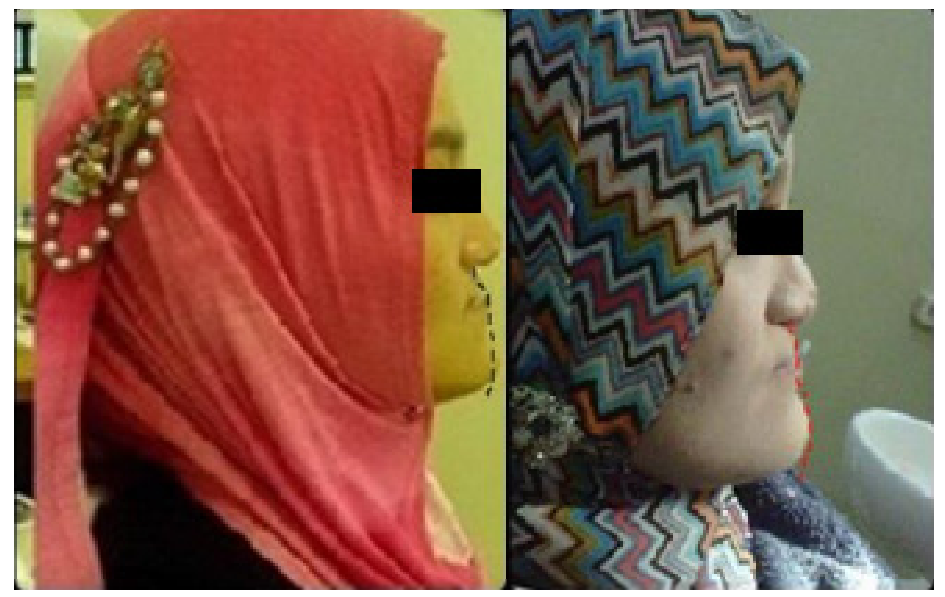

Gambar 17. Perbandingan profil pasien saat memakai gigi tiruan lama dan setelah memakai gigi tiruan overlay

Gigi tiruan lepasan overlay thermoplastic resin merupakan pilihan yang tepat, karena dapat mengkoreksi segi estetis dan kenyamanan pasien. Bagian anterior dibentuk sesuai lengkung rahang bawah yang normal, untuk memberi dukungan pada bibir atas, sehingga dapat menutupi daerah defek dan memperbaiki profil pasien.

Penggunaan thermoplastic resin dipilih karena memiliki fleksibilitas yang lebih baik dari resin akrilik. Fleksibilitas yang baik memungkinkan fitting surface gigi tiruan mengikuti kontur mukosa yang meningkatkan kenyamanan pemakaian.

\section{KESIMPULAN}

Gigi tiruan overlay thermoplastic resin menjadi pilihan perawatan kasus celah bibir dan palatum yang dapat meningkatkan estetis dan kenyamanan pasien.

\section{DAFTAR PUSTAKA}

1. Rahn AO, Boucher LJ. Maxillofacial Prosthetics Principles and Concepts, London. WB Saunders Company: 1970; 188.

2. Mese A, Ozdemir E. Removable partial denture in a cleft lip and palate patient : a case report , J Korean Med Sci 2008 ; 23 : 924-7.
3. Freitas JA, Almeida ALPF, Soares S, Neves LT, Garib DG, Trindade-Suendam IK, Yaedu RYF, Lauris RCMC, Oliviera TM, Pinto JHN. Rehabilitative treatment of cleft lip and palate experience of the Hospital for the Rehabilitation of Craniofacial Anomalies / USP (HRAC/USP) - Part 4 : Oral Rehabilitation, $J$ Appl Oral Sci 2013; 21(3): 284-92.

4. Ali R, Nixon PJ, Chan FWY. Restorative Management of the Cleft Patient: CLP Series Part 10, Ortho Update 2014; 7: 42-47.

5. Strickland F, Psillakis JJ, Grbic JT, Wright RF. Prosthodontic rehabilitation of the adult cleft palate patient : a case report, Columbia Dental Review 2004 ; 9: 1-9.

6. Kalpana C, Vamsi Prasad K. Seeing the unseen : preventive prosthodontics : use of overlay removable dental prosthesis. Annals and Essens of Dentistry 2010 ; 2(3): 44-49.

7. Brewer AA, Fenton AH. The overdenture, Dent Clin North Am. 1973; 17: 723-46.

8. Johnson A, Winstanley RB: Use of simple overdentures in the treatment of young patients with developmental anomalies, Quintessence. 1987; 11: 27-33. 